OPEN ACCESS

Edited by:

Puneeth lyengar

University of Texas Southwestern

Medical Center, United States

Reviewed by:

Francesco Cortiula,

Maastricht University Medical Centre

Netherlands

*Correspondence:

Gulistan Bahat

gbahatozturk@yahoo.com

tORCID:

Zumrut Bahat

orcid.org/0000-0002-1636-9393

Gulistan Bahat

orcid.org/0000-0001-5343-9795

Specialty section:

This article was submitted to

Radiation Oncology,

a section of the journal

Frontiers in Oncology

Received: 01 November 2021

Accepted: 06 December 2021

Published: 05 January 2022

Citation:

Bahat $Z$ and Bahat $G$ (2022)

Commentary: Association of

Sarcopenia with Toxicity and Survival

in Postoperative Recurrent

Esophageal Squamous Cell

Carcinoma Patients Receiving

Chemoradiotherapy.

Front. Oncol. 11:806858.

doi: 10.3389/fonc.2021.806858
Commentary: Association of Sarcopenia with Toxicity and Survival in Postoperative Recurrent Esophageal Squamous Cell Carcinoma Patients Receiving Chemoradiotherapy

\author{
Zumrut Bahat ${ }^{1 \dagger}$ and Gulistan Bahat ${ }^{2 *}$ \\ ${ }^{1}$ Department of Radiation Oncology, Faculty of Medicine, Karadeniz Technical University, Trabzon, Turkey, ${ }^{2}$ Department of \\ Internal Medicine, Division of Geriatrics, Istanbul Medical School, Istanbul University, Istanbul, Turkey
}

Keywords: sarcopenia, cancer, prognosis, radiotherapy, muscle strength, function

\section{A Commentary on}

Association of Sarcopenia with Toxicity and Survival in Postoperative Recurrent Esophageal Squamous Cell Carcinoma Patients Receiving Chemoradiotherapy

By Xu Y-Y, Zhou X-L, Yu C-H, Wang W-W, Ji F-Z, He D-C, Zhu W-G, and Tong Y-S (2021). Front. Oncol. 11:655071. doi: 10.3389/fonc.2021.655071

\section{INTRODUCTION}

In their valuable article, $\mathrm{Xu}$ et al. examined the prevalence of sarcopenia in postoperative recurrent esophageal squamous cell carcinoma (ESCC) patients receiving chemoradiotherapy (CRT). The authors studied the association of sarcopenia (S) with treatment-related toxicity and prognosis (overall survival, OS) as well (1). They included 184 patients over a 2-year period and assessed skeletal muscle area at the third lumbar vertebra. They adjusted skeletal muscle area by height ${ }^{2}$, defining low skeletal muscle mass as lower than $47.24 / \mathrm{cm}^{2} / \mathrm{m}^{2}$ in men and $36.92 / \mathrm{cm}^{2} / \mathrm{m}^{2}$ in women. They reported that $S$ was present in about half $(51.1 \%)$ of the patients. Patients with $S$ showed decreased OS (hazard ratio $=1.729,95 \%$ confidence interval $1.231-2.428, p=0.002$ ) in the multivariate analysis. In the multivariate model, the presence of sarcopenia was the most significant independent prognostic factor of poor OS $(p=0.002)$ followed by worse KPS and advanced tumor stage. While they reported that rates of grade 3-4 toxicities were higher in sarcopenic participants in univariate analyses, they did not study if $\mathrm{S}$ was an independent factor for treatment-related toxicities in multivariate analyses. 


\section{COMMENT ON THE FINDINGS AND DISCUSSION}

In this study, $\mathrm{S}$ was considered as the presence of low muscle mass. $S$ was defined as an age-related loss of skeletal muscle mass (SMM) at its first conceptualization. Yet, many studies reported that low skeletal muscle function is related to survival and other adverse outcomes as well, even more than the $\operatorname{LMM}(2,3)$. Moreover, loss of muscle strength starts earlier than the mass and develops faster than the loss of mass. Accordingly, all updated consensus reports signified and integrated muscle strength/ function as one of the two principal components of $S$ in addition to the other principal component, LMM (4).

In practice, the clinicians already order abdominal CT/MRI for routine work-up, and this allows evaluating the regional skeletal muscle mass. Hence, recently similar studies have been carried out to examine if $S$ is independently related to survival and other outcomes in cancer patients (5-9). Overall, in these studies, $S$ was not associated with OS when considered as the presence of LMM. However, $\mathrm{S}$ was associated with OS when it was defined as the simultaneous presence of LMM and muscle strength/function. In a very recent consensus report on the definition of $S$, it has been signified that the studies on secondary $\mathrm{S}$ ignore the integration of impaired muscle strength/function into the diagnosis of S, albeit its current definition. Accordingly, they recommended that $S$ studies in cancer as well should integrate low muscle strength/function in the definition of $S$ in these studies (10). We suggest that if the authors would have integrated the presence of low muscle strength into the definition of S, they would find much higher association between $\mathrm{OS}$ and $\mathrm{S}$, emphasizing the unique importance of $\mathrm{S}$ in the prognosis and assessment of the participants.

Why sarcopenia defined as LMM fails to correlate with survival in the majority of the studies, compared to when it is defined as loss of muscle strength and/or LMM + muscle strength, deserves attention and may be due to various factors.

\section{REFERENCES}

1. Xu YY, Zhou XL, Yu CH, Wang WW, Ji FZ, He DC, et al. Association of Sarcopenia With Toxicity and Survival in Postoperative Recurrent Esophageal Squamous Cell Carcinoma Patients Receiving Chemoradiotherapy. Front Oncol (2021) 11:655071. doi: 10.3389/fonc.2021.655071

2. Li R, Xia J, Zhang XI, Gathirua-Mwangi WG, Guo J, Li Y, et al. Associations of Muscle Mass and Strength With All-Cause Mortality Among US Older Adults. Med Sci Sports Exerc (2018) 50(3):458-67. doi: 10.1249/MSS.0000000000001448

3. Han P, Chen X, Yu X, Zhang Y, Song P, Cai M, et al. The Predictive Value of Sarcopenia and Its Individual Criteria for Cardiovascular and All-Cause Mortality in Suburb-Dwelling Older Chinese. J Nutr Health Aging (2020) 24(7):765-71. doi: 10.1007/s12603-020-1390-8

4. Cruz-Jentoft AJ, Bahat G, Bauer J, Boirie Y, Bruyère O, Cederholm T, et al. Sarcopenia: Revised European Consensus on Definition and Diagnosis. Age Ageing (2019) 48(1):16-31. doi: 10.1093/ageing/afy169

5. Kilgour RD, Vigano A, Trutschnigg B, Lucar E, Borod M, Morais JA, et al. Handgrip Strength Predicts Survival and Is Associated With Markers of Clinical and Functional Outcomes in Advanced Cancer Patients. Support Care Cancer (2013) 21(12):3261-70. doi: 10.1007/s00520-013-1894-4

6. Hua X, Liu S, Liao JF, Wen W, Long ZQ, Lu ZJ, et al. When the Loss Costs Too Much: A Systematic Review and Meta-Analysis of Sarcopenia in Head and Neck Cancer. Front Oncol (2019) 9:1561. doi: 10.3389/fonc.2019.01561
First, muscle strength (i.e., handgrip strength) has been shown to predict mortality and was associated with not only body composition changes but also nutritional status, inflammation, quality of life, and functionality as well, in multiple chronic diseases and advanced cancer patients $(5,11)$. Muscle strength may also capture important aspects of the adverse pathophysiological processes associated with cancer and aging (11). As an example, primary and secondary hypogonadism is seen as a complication in male cancer patients and is a wellknown triggering factor for loss of muscle strength (12). The downregulation of IGF-1 expression in skeletal muscle might also be one of the factors playing an important role in the development of muscular atrophy in cancer patients, such as in those treated with chemotherapy (13). These strength-related hormonal factors, i.e., testosterone (14) and insulin-like growth factor-I $(15,16)$, which decline with the presence of cancer and muscle strength, might explain why strength appears to be such a powerful marker of risk. Furthermore, the loss of motor neurons with aging results in an increase in the size of the remaining motor units, but with greater preservation of type 1 fibers, resulting in preservation of mass with relatively fewer type 2 fibers and thus lower strength (17). This point may explain the better association of muscle strength than that of muscle mass in cancer patients, particularly in older ones.

In conclusion, we propose that clinicians should concentrate on muscle strength/function as well while studying sarcopenia and its association with cancer and treatment-related outcomes.

\section{AUTHOR CONTRIBUTIONS}

ZB: Writing-Original Draft Preparation and Editing. GB: Review and Editing. All authors contributed to the article and approved the submitted version.

7. Fujiwara N, Nakagawa H, Kudo Y, Tateishi R, Taguri M, Watadani T, et al. Sarcopenia, Intramuscular Fat Deposition, and Visceral Adiposity Independently Predict the Outcomes of Hepatocellular Carcinoma. J Hepatol (2015) 63(1):131-40. doi: 10.1016/j.jhep.2015.02.031

8. Yip C, Goh V, Davies A, Gossage J, Mitchell-Hay R, Hynes O, et al. Assessment of Sarcopenia and Changes in Body Composition After Neoadjuvant Chemotherapy and Associations With Clinical Outcomes in Oesophageal Cancer. Eur Radiol (2014) 24(5):998-1005. doi: 10.1007/s00330-014-3110-4

9. Matsuoka H, Nakamura K, Matsubara Y, Ida N, Nishida T, Ogawa C, et al. Sarcopenia Is Not a Prognostic Factor of Outcome in Patients With Cervical Cancer Undergoing Concurrent Chemoradiotherapy or Radiotherapy. Anticancer Res (2019) 39(2):933-9. doi: 10.21873/anticanres.13196

10. Bauer J, Morley JE, Schols AMWJ, Ferrucci L, Cruz-Jentoft AJ, Dent E, et al. Sarcopenia: A Time for Action. An SCWD Position Paper. J Cachexia Sarcopenia Muscle (2019) 10(5):956-61. doi: 10.1002/jcsm.12483

11. Newman AB, Kupelian V, Visser M, Simonsick EM, Goodpaster BH, Kritchevsky SB, et al. Strength, But Not Muscle Mass, Is Associated With Mortality in the Health, Aging and Body Composition Study Cohort. J Gerontol: Ser A (2006) 61(1):72-7. doi: 10.1093/gerona/61.1.72

12. Wright TJ, Dillon EL, Durham WJ, Chamberlain A, Randolph KM, Danesi C, et al. A Randomized Trial of Adjunct Testosterone for Cancer-Related Muscle Loss in Men and Women. J Cachexia Sarcopenia Muscle (2018) 9(3):482-96. doi: $10.1002 /$ jcsm. 12295 
13. Sakai H, Asami M, Naito H, Kitora S, Suzuki Y, Miyauchi Y, et al. Exogenous Insulin-Like Growth Factor 1 Attenuates Cisplatin-Induced Muscle Atrophy in Mice. J Cachexia Sarcopenia Muscle (2021). doi: 10.1002/jcsm.12760

14. Bhasin S. Testosterone Supplementation for Aging-Associated Sarcopenia. J Gerontol A Biol Sci Med Sci (2003) 58(11):1002-8. doi: 10.1093/gerona/ 58.11.M1002

15. Cappola AR, Bandeen-Roche K, Wand GS, Volpato S, Fried LP. Association of IGF-I Levels With Muscle Strength and Mobility in Older Women. J Clin Endocrinol Metab (2001) 86(9):4139-46. doi: 10.1210/jcem.86.9.7868

16. Harris TB, Kiel D, Roubenoff R, Langlois J, Hannan M, Havlik R, et al. Association of Insulin-Like Growth Factor-I With Body Composition, Weight History, and Past Health Behaviors in the Very Old: The Framingham Heart Study. J Am Geriatr Soc (1997) 45(2):133-9. doi: 10.1111/j.1532-5415.1997.tb04497.x

17. Andersen JL. Muscle Fibre Type Adaptation in the Elderly Human Muscle. Scand J Med Sci Sports (2003) 13(1):40-7. doi: 10.1034/j.1600-0838. 2003.00299.x
Conflict of Interest: The authors declare that the research was conducted in the absence of any commercial or financial relationships that could be construed as a potential conflict of interest.

Publisher's Note: All claims expressed in this article are solely those of the authors and do not necessarily represent those of their affiliated organizations, or those of the publisher, the editors and the reviewers. Any product that may be evaluated in this article, or claim that may be made by its manufacturer, is not guaranteed or endorsed by the publisher.

Copyright (๑) 2022 Bahat and Bahat. This is an open-access article distributed under the terms of the Creative Commons Attribution License (CC BY). The use, distribution or reproduction in other forums is permitted, provided the original author(s) and the copyright owner(s) are credited and that the original publication in this journal is cited, in accordance with accepted academic practice. No use, distribution or reproduction is permitted which does not comply with these terms. 